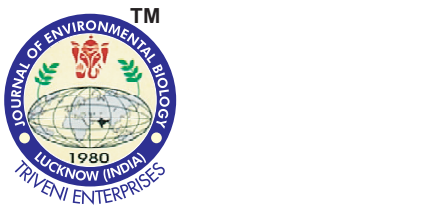

DOI : http://doi.org/10.22438/jeb/39/4/MRN-681
Journal of Environmental Biology

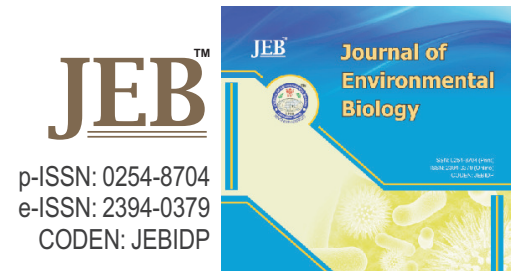

\title{
Heavy metal investigation and risk assessment along the Le'An River from non-ferrous metal mining and smelting activities in Poyang, China
}

\section{Abstract}

Authors Info

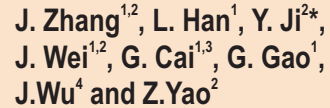

${ }^{1}$ Ministry of Education Key Laboratory of Integrated Regulation and Resource Development on Shallow Lakes, Hohai University, Nanjing, 210 098, PR China

${ }^{2}$ College of Water Conservancy and Ecological Engineering, Nanchang Institute of Technology, Nanchang, 330 099, China

${ }^{3}$ Jiang Xi Engineering

Research Center of Water Engineering Safety and Resources Efficient Utilization, Nanchang, 330 099, China

${ }^{4}$ Shanghai Academy of Environmental Sciences, Shanghai, 200 233, China

*Corresponding Author Email : jiyong@nit.edu.cn

Key words

Le'An Basin

Mining activities

Non-ferrous metals

Risk assessment

Sediments

\section{Publication Info}

Paper received : 19.06.2017

Revised received : 08.11.2017

Re-revised received : 29.12 .2017

Accepted : 16.01.2018
Aim : In this study, statistical methods and visualization were used to study the distribution of heavy metals and the potential hazards to the aquatic ecosystem along the main waterway of the Le'An Basin. This waterway has been severely polluted with heavy metals as a result of mining activities.

Methodology : A total of 22 surface sediment samples were collected from sampling sites in four typical areas representing the entire Le'An river. We compared the measured results to the background values. The geo-accumulation index $\left(\mathrm{I}_{\text {geo }}\right)$, integrated pollution load index (PLI) and sediment quality standard combined with statistical methods were used to assess the degree of pollution, their potential sources and ecosystem risk level.

Results : Sites near Shanggukou Bridge and downstream of the intersection of the Le'An and Jishui Rivers had the highest pollution levels of $\mathrm{Cu}, \mathrm{Zn}, \mathrm{Cd}$ and As. In addition to the background areas (BA), both $I_{\text {geo }}$ values and PLI indicated that all the sites were class 4, 5 and 6 types. Upstream areas (UA) and middle stream areas (MA) were considered to be highly polluted. Based on the geochemical partitioning analysis and the ratios between secondary phase and primary phase (RSP) values, the results revealed that higher concentrations of $\mathrm{Cu}, \mathrm{Pb}, \mathrm{Cd}$ and $A$ s in the UA and MA were likely to be harmful to the aquatic

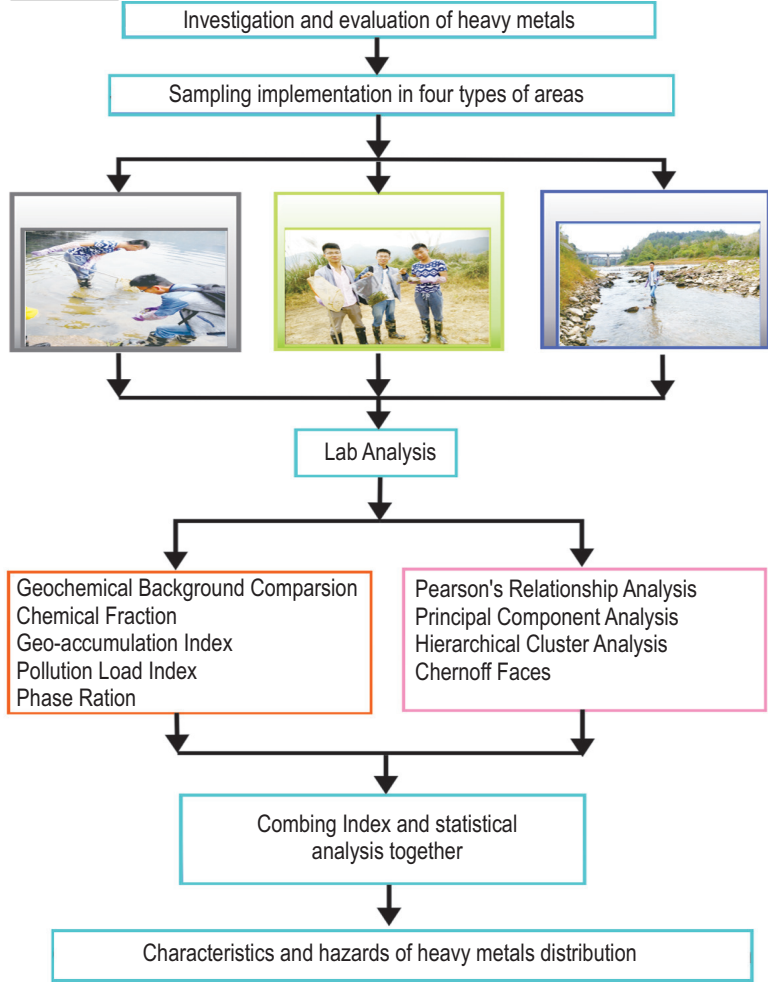
organisms in these areas. Principal Component Analysis (PCA) and Hierarchical Cluster Analyses (HCA) revealed that $\mathrm{Cu}, \mathrm{Zn}, \mathrm{Pb}, \mathrm{Cd}, \mathrm{Cr}$ and $\mathrm{As}$ were sourced from many complicated anthropogenic sources.

Interpretation : Metallic discharges from non-ferrous mine plants and township enterprises contributed the largest portion of sediment pollutants. The visualization technique of Chernoff faces were useful for representing and interpreting the multidimensional data. 


\section{Introduction}

Heavy metals are important mined industrial materials but also toxic environmental contaminants (Zhu et al., 2017). They are necessary or beneficial in nature at certain levels but also pose a great threat to human health when their concentrations exceed the permissible limit (Mehr et al., 2017). High concentrations in the natural environment are often the result of anthropogenic activities such as agriculture, construction, industry and mining (Ji et al., 2017). Severe heavy metal contamination often occurs in areas near mines and smelting sites (Ji et al., 2017). During production of non-ferrous metals, large volume of waste water containing high concentrations of heavy metals are inevitably produced. In some cases, waste water is discharged directly into the aquatic environments contributing a high pollution load to the water ecosystem and having a negative inpact on the local environment (Hasayen et al., 2017). Mining activities can also lead to deterioration of soil quality, decrease soil density, organic matter, total nitrogen and available phosphorus content and destroy ecosystem's functionality.

Heavy metals are transported into aquatic ecosystems by rainfall runoff. They are mixed with particulate matter, suspended in the water body and deposited in sediment (Samanta et al., 2005). Concentration of heavy metals in sediments exceed those in the overlying water by three to five orders of magnitude (Bryan and Langston, 1992). These pollutants may also serve as sources of contamination when the external environment changes and they are released back into the overlying water. Acid waste water from mines is the most common environmental problem associated with mining, especially when this water contains sulphide materials such as pyrite (Sheoran and Sheoran, 2006). Chemical reactions, that occur when sulphide materials are exposed to water and oxygen, may subsequently produce acidic waste water. In addition, acidification also increase dissolution of some toxic heavy metals. In summary, mining activities cause large negative impacts on many environmental components, including the air, water, sediments, soils, animals and plants (Hilson and Murck, 2000).

Lake Poyang, located in Jiangxi Province, China and on the southern bank of the Yangtze River, is the largest freshwater inland lake and the largest wetland preserve for migrating birds in China. More than $98 \%$ of the world bird species migrate through this area. As a result, Lake Poyang has attracted the attention of the entire world (Ji et al., 2014, 2015). However, the ecosystem in these areas has been polluted due to the construction of the Ecological Economic Zone around Lake Poyang and rapid development of local economy in recent years. The Rao River, one of the main "Five Branches" connected to Lake Poyang, is mainly composed of the Le' An and Changjiang Rivers, which has the largest catchment area in northeastern Jiangxi province. Presently, the Le'An River is severely polluted by heavy metals, mainly due to mining activities (Chen et al., 2016).
Mining activities continuously emit large amounts of acidic waste water that contain heavy metals. This has led to the accumulation of high concentrations of heavy metal in local soils and waterway systems (Yu et al., 2016). Thousands of acres of downstream rice fields have been polluted by heavy metals and are now unsuitable for agricultural use. The Le'An River was selected as the study area (Fig. 1). Sediment samples were collected according to the equal distances principle from upstream to downstream. We aimed to: (1) determine the distribution and partition characteristics of heavy metals $(\mathrm{Cu}, \mathrm{Zn}$, $\mathrm{Pb}, \mathrm{Cd}, \mathrm{Cr}$, As and $\mathrm{Ni}$ ) by combining geochemical partitioning analysis and the ratios between secondary and primary phase $(R S P)$ values; (2) identify the potential heavy metal sources using PCA and HCA; (3) assess the degree of pollution by calculating the geo-accumulation $\left(l_{\text {geo }}\right)$ index and the integrated pollution load index (PLI) and comparing them with sediment quality values (SQVs); and (4) present multidimensional data using the visualization technique of the Chernoff face.

\section{Materials and Methods}

Study area : The study area mainly consisted of mountains and hills, with plains distributed in the downstream areas accounting for only a small portion (Fig. 1). In the present study, a total of 22 sections located in four areas (BA, UA, MAand DA) were sampled using the equidistant principle, combined with terrain, river sinuosity changes, tributary intersections and other factors.

Sampling, preparation and analysis : At each site, 4-5 samples (at depths of 0-20 cm from the surface) were extracted using a stainless steel grab sampler at equal distances and mixed together to represent the sample site. Samples were dried at room temperature. Samples taken at the same section were ground with a mortar, passed through a $0.15 \mathrm{~mm}$ mesh sieve and stored in a zip lock bag at $-4^{\circ} \mathrm{C}$ prior to laboratory analyses.

For the total concentration analysis, approximately 0.1 $\mathrm{g}$ of each sample was weighed and placed into a $50 \mathrm{ml}$ conical flask. After wetting with several drops of ultra pure water, 5-8 $\mathrm{ml}$ of concentrated nitric acid and a few drops of perchloric acid were added stepwise. The samples were heated on an electric heating plate at $250^{\circ} \mathrm{C}$ for digestion until a white color was detected. For the chemical partitioning analyses, an improved European Community Bureau of Reference (BCR) method defined the partition elements into four operationally defined geochemical fractions, including acid soluble, reducible, oxidizable and residual fractions (Zimmerman and Weindorf, 2010). The concentrations of the metals in the solutions were analysed using inductively coupled plasma-atomic emission spectrometry (ICP-AES). GSD-9 and GSD-11, supplied by the Chinese Academy of Geological Sciences, were used to ensure the accuracy of the analytical determination. Two method blanks and two spiked blanks were processed simultaneously. The relative standard deviation (RSD) of the replicate analysis was less than $6.3 \%$ and the regression coefficient of the calibration standards for different heavy metals was greater 
than 0.999 .

Evaluation of contamination degree : The geo-accumulation index $\left(l_{\text {geo }}\right)$ assess the degree of heavy metal pollution (Müller, 1969) and this method has been widely used by scholars worldwide as it considers the effects of natural geological processes on heavy metal background as well as addresses inpact of human activities on heavy metal pollution in sediments (Dou et al., 2013; Zahra et al., 2014; Mohammad Ali et al., 2015). An integrated pollution index considering the effect of human activities on heavy metal pollution was proposed by Tomlinson et al. (1980), to evaluate the degree and density of contamination. The Chernoff Faces Graph proposed by Chernoff (1972), is capable of processing multi-dimensioned data by associating an attribute to a facial characteristic, such as face shape, eye size, nose width. The face graph drawing in this research was performed using the SPLUS 8.0.4 software, which has 15 variables. By calculating the ratio between the secondary and primary phases (RSP), we can distinguish between the potential anthropogenic and natural sources of heavy metal pollution:

$$
\mathrm{RSP}=\left(\mathrm{F}_{1}+\mathrm{F}_{2}+\mathrm{F}_{3}\right) / \mathrm{F}_{4}
$$

where, $F_{1}, F_{2}, F_{3}$ and $F_{4}$ are the four kinds of heavy metal contents, respectively, extracted using the European Community Bureau of Reference (BCR) method. Heavy metal pollution can be classified into four grades based on the RSP values (Grade 1 , Unpolluted: $R S P<1$; Grade 2, lightly polluted: $1 \leq R S P<2$; Grade 3 , moderately polluted: $2 \leq \mathrm{RSP}<3$; Grade 4 , highly polluted: $3 \leq$ RSP).

\section{Results and Discussion}

Total concentration and chemical partitioning analysis : The heavy metal concentrations were distributed over a large range (Table 1). Higher amounts of contaminants were found near areas experiencing mining activities, industrial parks or centres of township enterprises. Human activities, such as non-ferrous mining and the industrial processing of ores and metals, appear to be the main sources for accumulation of heavy metals discharged into the aquatic ecosystem (Soto-Jiménez and Flegal, 2011). The contents analysed in different areas decreased in the following order: $\mathrm{Cu}, \mathrm{Cd}$ and $\mathrm{As}: \mathrm{UA}>\mathrm{MA}>\mathrm{DA}>\mathrm{BA} ; \mathrm{Zn}$ and $\mathrm{Pb}: \mathrm{MA}>\mathrm{DA}>$ $\mathrm{UA}>\mathrm{BA}$ (Table 1).

Excluding S4, which receives light pollution from Wuyuan County, the BA area is relatively uncontaminated and has no obvious domestic, industrial or agricultural pollution sources. S6 and $\mathrm{S} 9$, located in UA and MA respectively, have severe pollution as a result of their location. S6 is situated near Shanggukou Bridge, where a connection for waste water coming from the

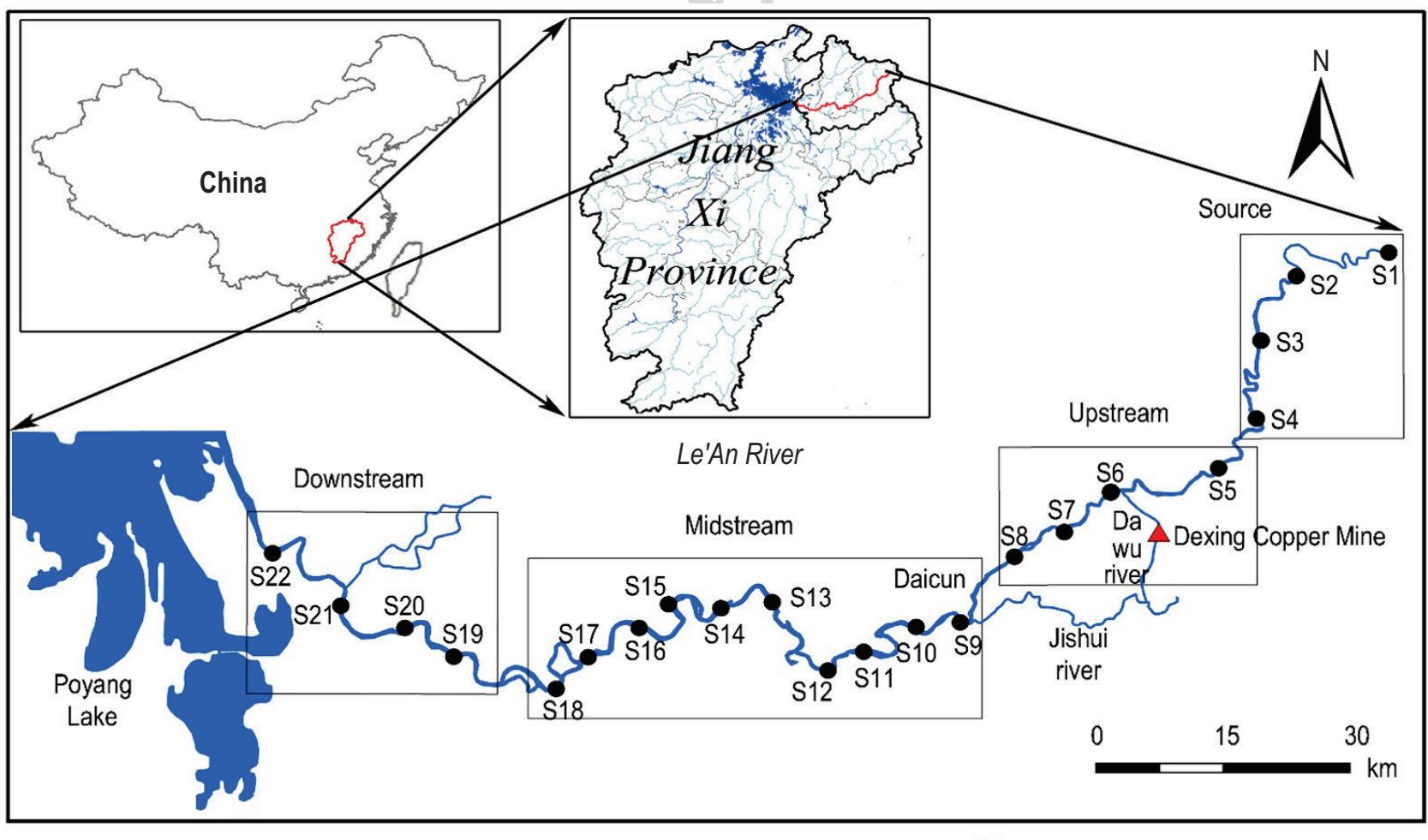

- Sampling section

$\Delta$ Dexing copper mine

- River

Lake

Fig. 1 : Map showing the research area and the geographical location of the sampling sites 
Dexing Copper Mine is located. S9 is downstream of the intersection of the Le'An and Jishui River, where waste water from non-ferrous mining industries along the Jishui River is discharged into the Le'An River. Some township enterprises were not established in an orderly manner, creating more serious contamination in local areas. $\mathrm{S17}$, which has the highest $\mathrm{Pb}$ and $\mathrm{Cr}$ concentrations, is located approximately $5 \mathrm{~km}$ downstream of Zhenqiao Town, which is a centre for shipbuilding, paper making, and water transportation. This area constantly experiences expanding land demands due to local economic development.

The elemental composition of river particulates in eastern China were taken as background values (Chen and Wang, 1996). Dividing the background values by the analysed samples indicates that the concentrations of heavy metals in the study was considerably far higher than their corresponding geochemical background values. This is especially true for the UA areas,

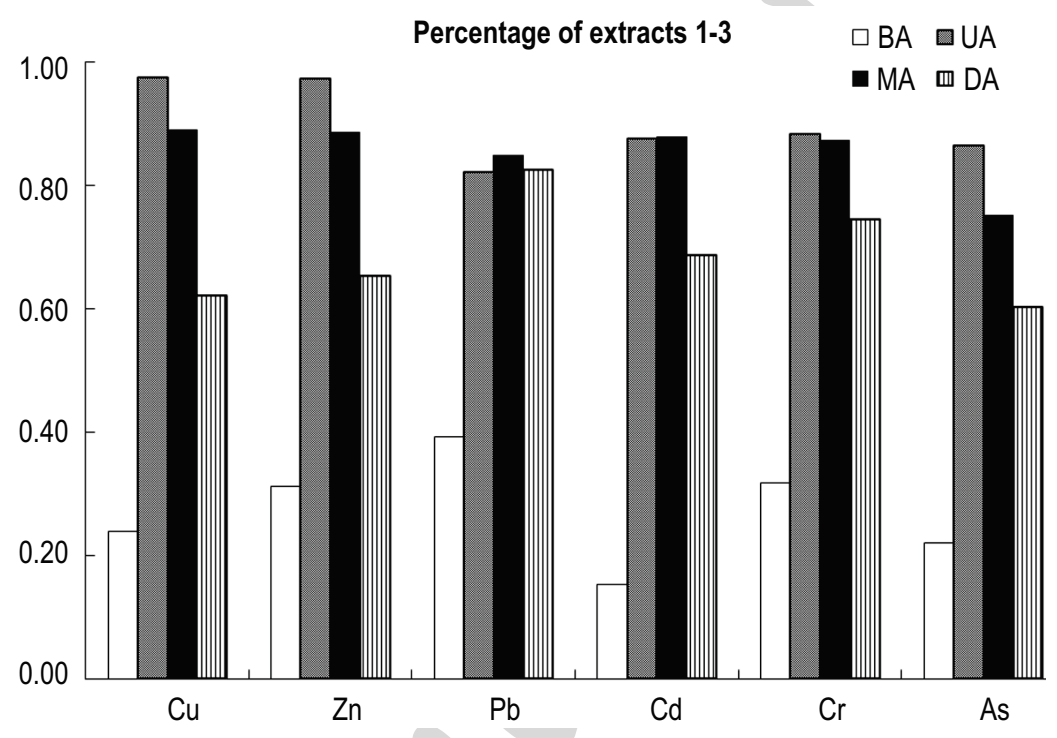

Fig. 2 : Metals extracted from fractions 1-3 as a percentage of total metal concentration

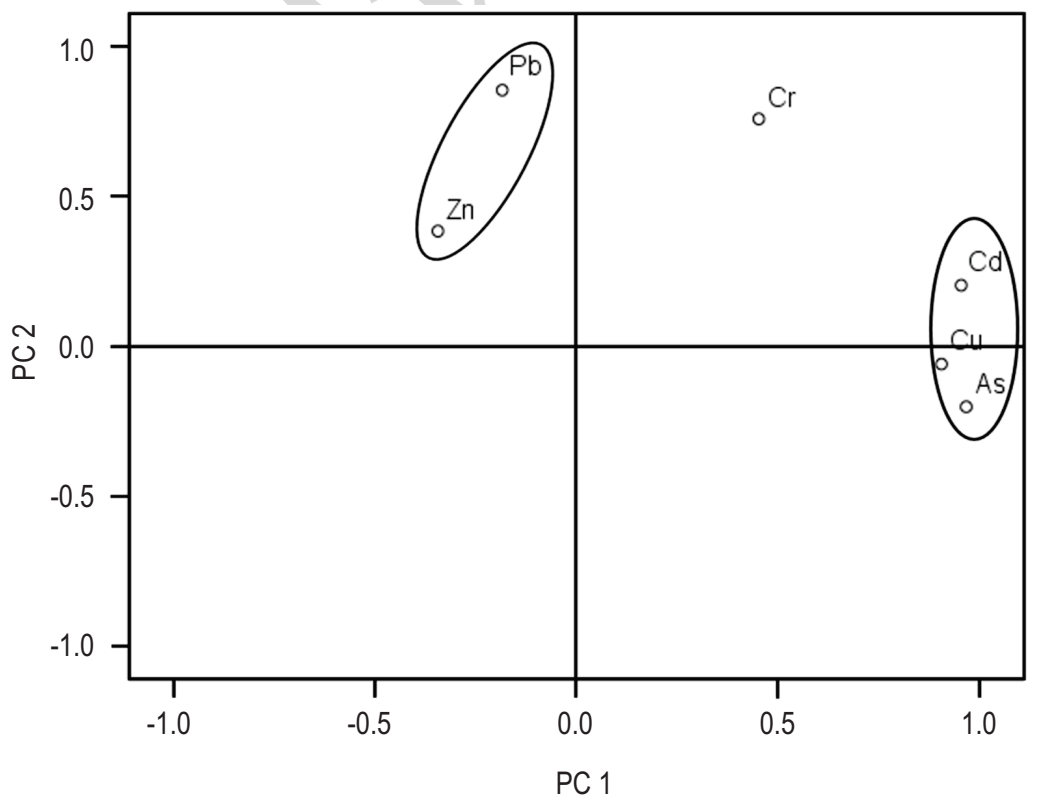

Fig. 3 : Loading plot of the pollutants in the space defined by two component 
Table 1 : Means of metal concentration analyzed in sediments collected from BA, UA, MA and DA

\begin{tabular}{|c|c|c|c|c|c|c|c|}
\hline Site & Location & $\mathrm{Cu}$ & $\mathrm{Zn}$ & $\mathrm{Pb}$ & $\mathrm{Cd}$ & $\mathrm{Cr}$ & As \\
\hline \multirow{4}{*}{ BA } & $\mathrm{S} 1$ & 9.33 & 55.12 & 12.79 & 0.51 & 20.06 & 12.82 \\
\hline & S2 & 7.12 & 52.54 & 12.66 & 0.48 & 44.56 & 14.11 \\
\hline & S3 & 17.21 & 112.71 & 18.00 & 0.87 & 124.87 & 17.07 \\
\hline & S4 & 27.40 & 204.40 & 35.81 & 1.12 & 87.05 & 15.32 \\
\hline \multirow{4}{*}{ UA } & S5 & 35.89 & 401.66 & 63.48 & 2.03 & 160.34 & 19.76 \\
\hline & S6 & 2964.87 & 1938.13 & 815.65 & 68.89 & 358.12 & 433.04 \\
\hline & S7 & 2273.87 & 1705.63 & 734.07 & 47.06 & 259.93 & 340.52 \\
\hline & S8 & 1884.54 & 1792.58 & 665.67 & 41.99 & 273.13 & 277.06 \\
\hline \multirow{10}{*}{ MA } & s9 & 1976.07 & 3008.20 & 1129.22 & 42.38 & 228.90 & 187.97 \\
\hline & S10 & 2210.09 & 2937.10 & 1067.88 & 33.65 & 247.78 & 205.05 \\
\hline & S11 & 1888.40 & 2703.32 & 1062.20 & 34.81 & 275.08 & 187.71 \\
\hline & $\mathrm{S} 12$ & 1701.49 & 2598.66 & 913.96 & 33.58 & 253.37 & 222.94 \\
\hline & $\mathrm{S} 13$ & 1467.40 & 2219.03 & 832.23 & 27.11 & 260.01 & 148.85 \\
\hline & S14 & 1218.98 & 2309.93 & 803.02 & 27.89 & 388.89 & 130.31 \\
\hline & $\mathrm{S} 15$ & 1010.34 & 2591.91 & 1033.02 & 45.43 & 433.30 & 158.01 \\
\hline & S16 & 1177.79 & 2579.03 & 1117.37 & 42.02 & 439.17 & 179.12 \\
\hline & S17 & 1503.30 & 2218.19 & 2023.99 & 38.20 & 466.56 & 160.47 \\
\hline & $\mathrm{S} 18$ & 1438.95 & 2300.04 & 1933.74 & 33.44 & 359.39 & 141.22 \\
\hline \multirow{11}{*}{ DA } & S19 & 1122.16 & 2376.40 & 1301.27 & 16.03 & 297.99 & 75.42 \\
\hline & $\mathrm{S} 20$ & 812.30 & 2454.76 & 1057.97 & 11.30 & 232.35 & 56.11 \\
\hline & S21 & 577.96 & 2214.68 & 934.75 & 4.21 & 106.08 & 78.88 \\
\hline & $\mathrm{S} 22$ & 334.34 & 2336.90 & 966.10 & 4.87 & 143.11 & 46.19 \\
\hline & Mean & 1166.35 & 1868.68 & 842.49 & 25.36 & 248.18 & 141.27 \\
\hline & STD & 861.32 & 997.45 & 557.44 & 19.76 & 127.44 & 112.09 \\
\hline & $\mathrm{CV}$ & 0.74 & 0.53 & 0.66 & 0.78 & 0.51 & 0.79 \\
\hline & Background $^{*}$ & 42.50 & 164.00 & 34.50 & 0.75 & 56.00 & 13.00 \\
\hline & River Xinjiang (Ji et al., 2015) & 49.52 & 141.79 & 35.28 & 3.75 & 28.02 & 6.49 \\
\hline & River Zhujiang (Zhu et al., 2017) & 39.02 & 110.85 & 59.43 & 0.34 & 56.40 & 5.24 \\
\hline & River Yangtz (Zhang et al., 2009) & 30.70 & 94.30 & 27.30 & 0.26 & 78.90 & $\mathrm{Na}$ \\
\hline
\end{tabular}

* Background values of heavy metals in Poyang Lake (Chen et al., 1996)

where $\mathrm{Cu}$ and $\mathrm{Cd}$ were 55.87 and 70.20 times greater, respectively, than their background values. Excluding site $\mathrm{S4}$, which is affected by upstream sewage, all the measured heavy metals from BA were below their corresponding background values. This indicates that no obvious contamination discharge occurred in these areas. For comparison purpose, the heavy metal concentrations from the present research and some other rivers in China are also listed in Table 1. The results show that levels of heavy metals in the Le'An River were significantly higher than those in the Zhujiang, Yangtze and Xingjiang Rivers (Ji et al., 2014; Wen et al., 2002; Zhang et al., 2009).

Aquatic ecosystems can suffer high risk and be destroyed when exposed to high concentrations of heavy metal pollutants. This is not only dependant on the total heavy metal content but is also a function of other chemical and geological fractions. Therefore, partition analysis of the pollutants offers more useful information on potential mobility and bio-availability, which can consequently provide a more realistic evaluation of the effects on the ecosystem (Jalali and Haemati, 2013). Metals extracted from fractions 1-3 are usually considered to represent potential anthropogenic sources and are used to indicate heavy metals mobility (Fig. 2). Excluding S5, which is situated upstream of the Dexing mining areas, the UA areas receiving the highest concentration of waste water had the highest risk for $\mathrm{Cu}, \mathrm{Cd}$ and As, while the MA areas ranging from the conjunction of Jishui River to Shizhen Town had the highest bioavailability of $\mathrm{Zn}, \mathrm{Pb}$ and $\mathrm{Cr}$. Analysis of second phase indicates that the percentage of metals partitioned in extracts 1-3 differed considerably among the sites in the following increasing order: $B A<D A<M A<U A$.

Assessing UA and MA, which includes the most polluted areas, reveal that almost all of the studied heavy metals had a higher percentage of "potential bioavailability". Over $80 \%$ of the metals partitioned towards fraction 1-3. This shows the effect of heavy metals contributed by anthropogenic activities, which have higher mobility and bioavailability. In particular, the second phase percentage of $\mathrm{Cu}$ and $\mathrm{Zn}$ in the UA areas were greater 


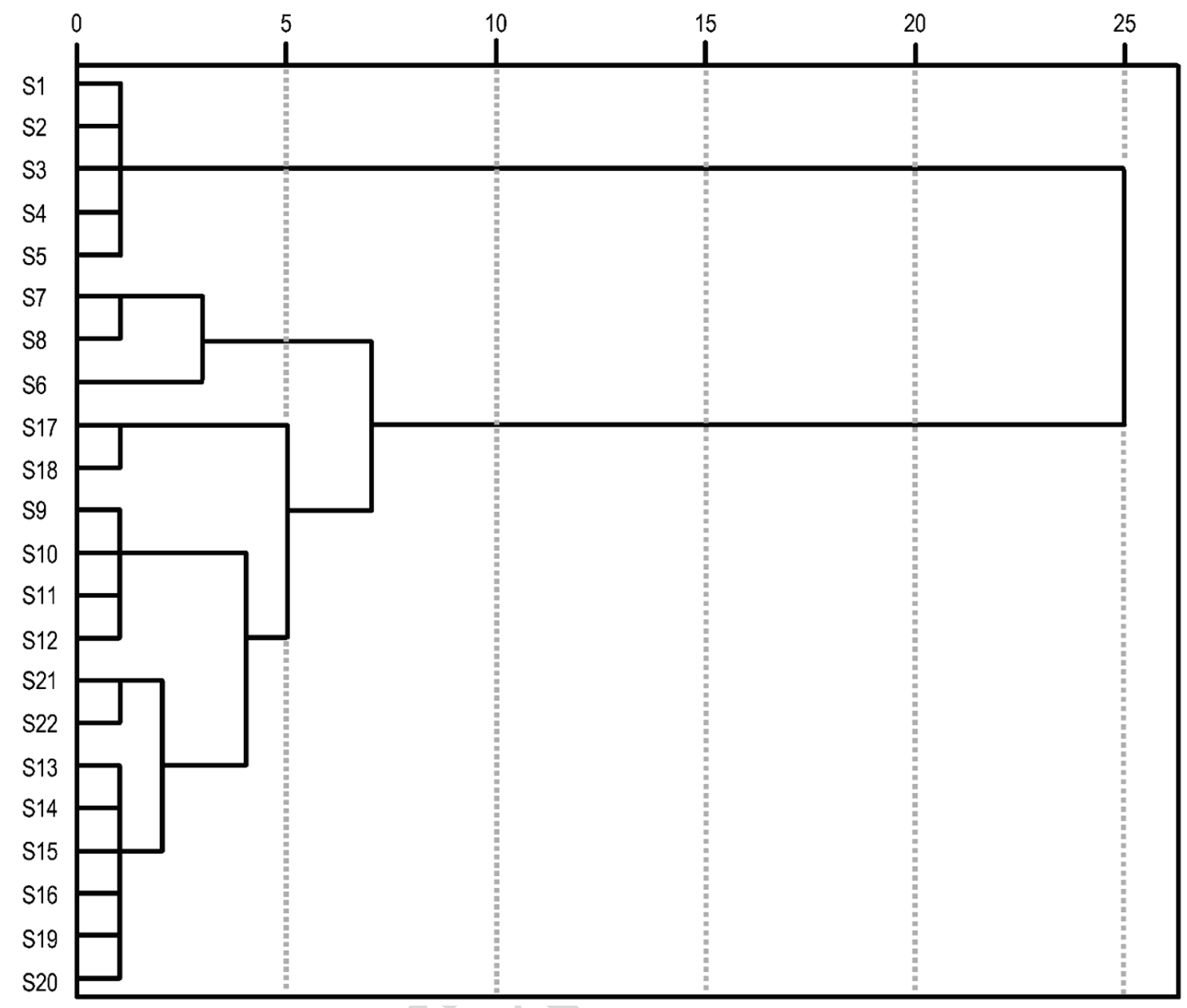

Fig. 4 : Dendrogram of the sediment sampling sites

than $90 \%$ Furthermore, Cu was usually detected in extracts 1 and 2 from heavily polluted sites. Bioavailable fraction percentage in the BAareas was compared with those in the other areas, it can be concluded that it had a lower value, with less than $30 \%$ of the metals partitioned in fraction $1-3$. This also indicates that natural sources of heavy metals are present in the residual fraction or primary phase and they are less toxic to aquatic organisms.

Sources and mobility analysis : Pearson correlation analysis was used to identify the relationship between different trace elements and their potential sources. Excluding S1 to S5, the values of $\mathrm{Cu}, \mathrm{Cd}$ and $\mathrm{As}$ at other stations had a significant positive correlation among each other, with values of 0.832 for $\mathrm{Cu}$ and $\mathrm{Cd}$, 0.905 for Cu and As and 0.885 for Cd and As (Table 2). The above results suggest that these heavy metals may be associated with each other in similar regions and have similar transport behaviour in aquatic environments. Pollution in the UA, MA and DA appear to be dominated by different industrial patterns. In the UA areas, non-ferrous mining activities, such as those of Dexing Copper, are the main human activities. In the MA and DA areas, township enterprise business and industrial parks, including the paper industry, printing enterprises and the chemical industry are distributed along the main river stream.

Heavy metal contamination exhibited great spatial variability in the mainstream Le'An River, suggesting that the contaminants may come from mixed sources. The principal factors obtained by principal component analysis (PCA) with eigenvalues greater than 1.0 extracted from the variables according to the Kaiser criterion are listed in Table 2. The first two factors with eigenvalues greater than 1.0 account for $76.17 \%$ of the total variance and are listed with a rotated loading matrix. These two factors are important in interpreting potential heavy metals in this study. Factor 1 was characterized by $\mathrm{Cu}, \mathrm{Cd}$ and $\mathrm{As}$ and these accounted for $50.51 \%$ of the total variance. Factor 2 was mainly dominated by $\mathrm{Pb}, \mathrm{Cr}$ and $\mathrm{Zn}$ and accounted for $25.66 \%$ of the total variance. This difference indicates that the heavy metal sources in the Le'An River are complex and arise from different sources. The loading plot (Fig. 3) interprets the potential clusters of different heavy metals. The heavy metal sources in the main UA mostly come from non-ferrous mining activities. 


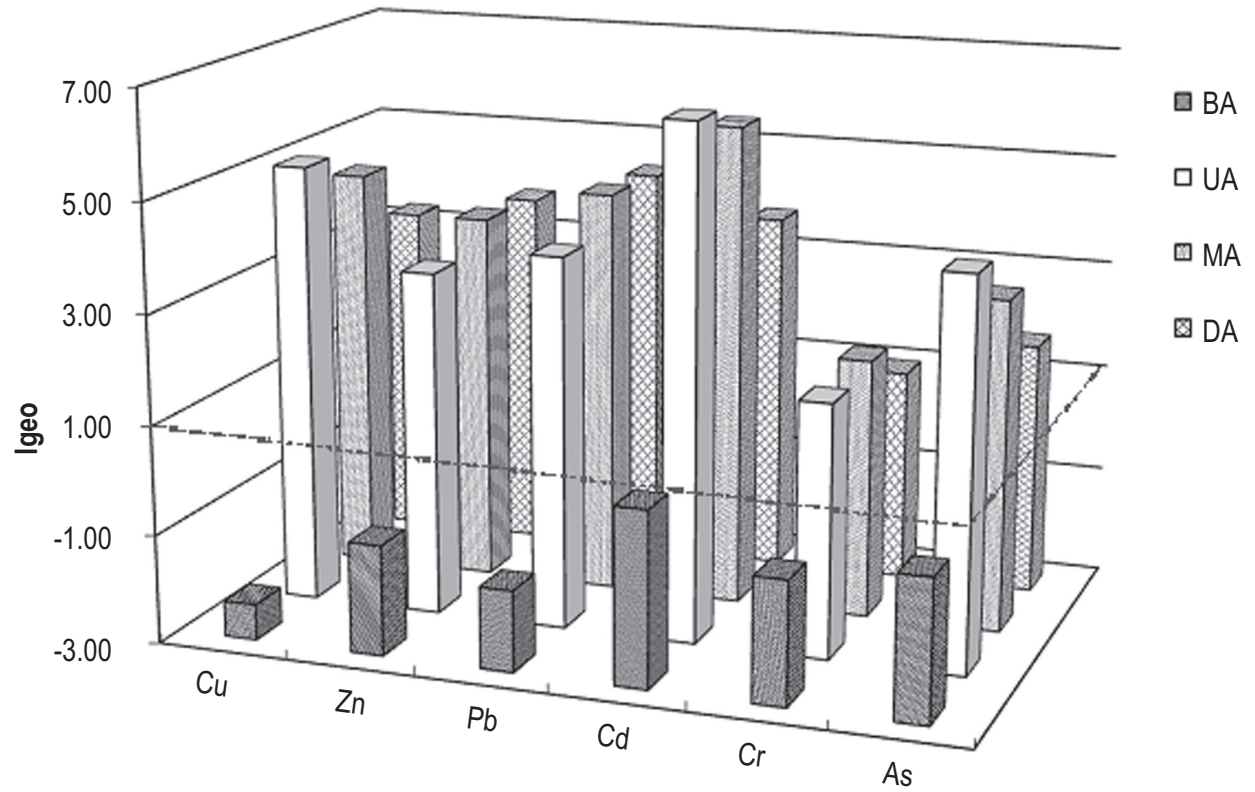

Fig. 5 : Statistical analysis of Geo-accumulation Index $\left(I_{g e o}\right)$ in the River Le'An
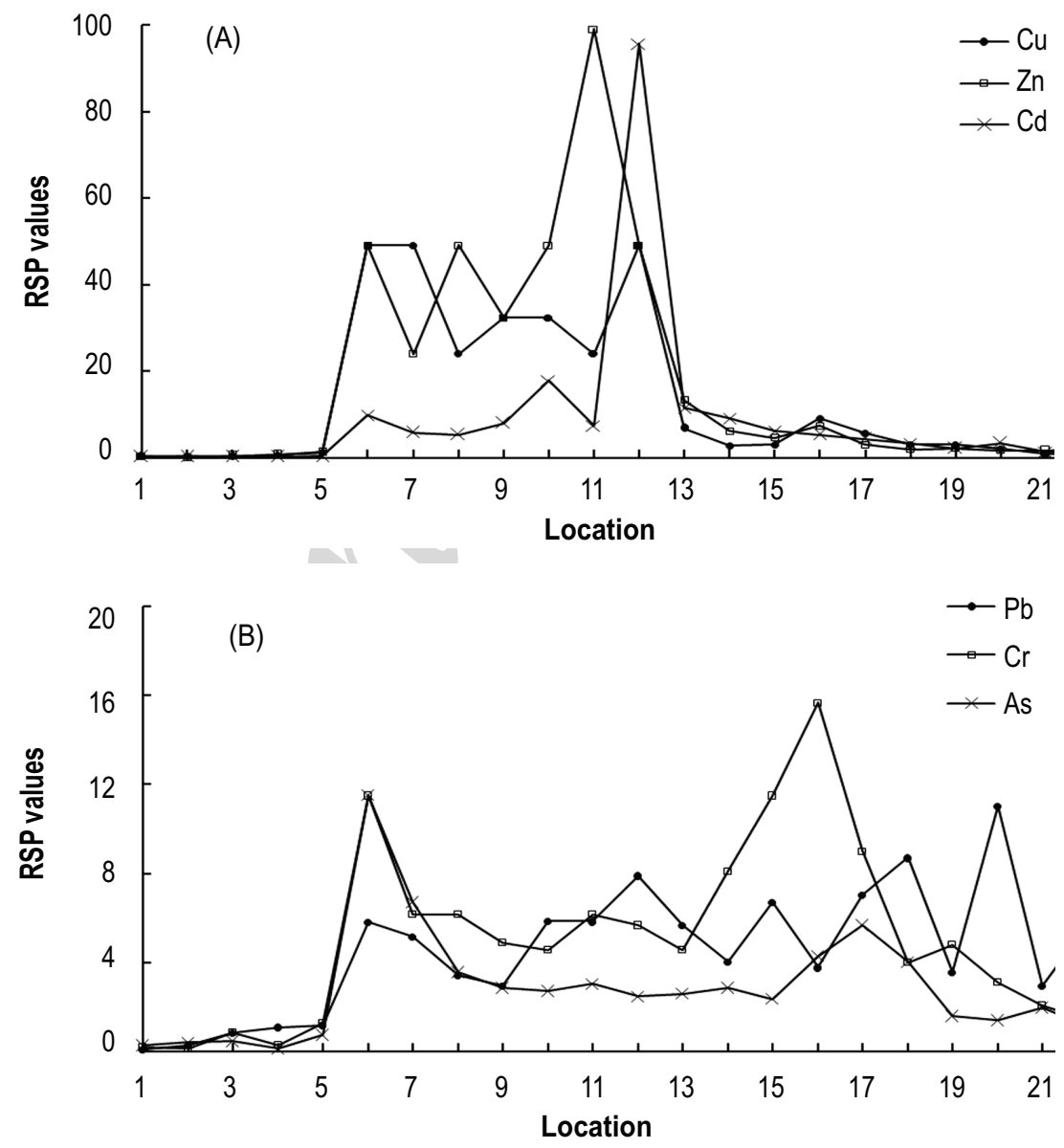

Fig. 6 : Statistical analysis of ratio of secondary phase and primary phase method (RSP) 


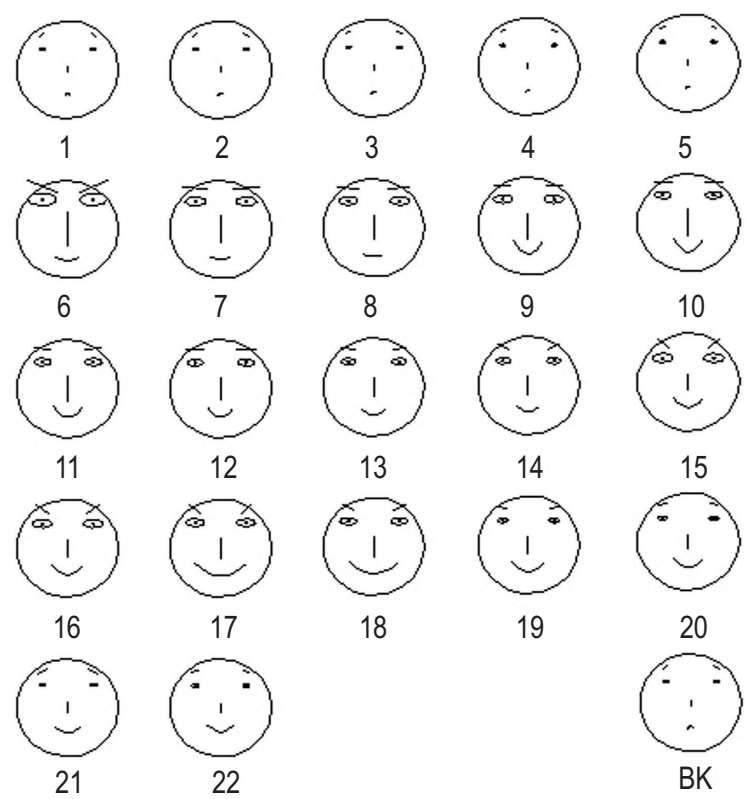

Fig. 7 : Chernoff faces for all sampling sites in the Le'An River

Hierarchical Cluster Analysis (HCA) is typically used to group different variables into diffrent clusters (Chabukdhara and Nema, 2012). Fig. 4 shows the cluster dendrogram result obtained by calculating the concentrations of heavy metals in the examined data matrix vs. those at individual sites. As a result sites sharing similar heavy metal characteristics are grouped into the same clusters. HCA was performed on the data using the Ward Method, where the squared Euclidean distance is used as a similarity measure. The sampling sites can be sorted into five categories: group 1 (including the entire batch of BA sites S1, S2, S3, S4 and S5, located near Haikou Town), group 2 (S6, S7 and S8 in UA areas, dominated by non-ferrous mining activities), group 3 (S17 and S18, mainly affected by township enterprise businesses), group 4 (S9, S10, S11 and $S 12$, located downstream of the intersection of the Le'An and Jishui Rivers) and group 5 (S13, S14, S15, S16, S19, S20, S21 and S22). It has been established that sites in the same clusters show similarities in terms of their pollution sources and characteristics (Idris et al., 2015).

Group 1 sites, located in the headstream areas of the Le'An River, are far from human activities and are relatively unpolluted. Group 2, where waste water containing high concentrations of heavy metals from copper mine activities is discharged into the river was heavily affected by highly contaminated sewage. Group 2 was identified as the most polluted area. Group 4, located just downstream of Group 2, was also directly affected by the heavily polluted water flow originating upstream and was classified as a cluster. Groups 3 and 5 were mainly affected by township enterprises, as they were both
Table 2 : Statistical results of Principal Components Analysis $(n=17)$

\begin{tabular}{|c|c|c|c|c|c|c|}
\hline \multicolumn{7}{|c|}{ Matrix to be factored } \\
\hline & $\mathrm{Cu}$ & $\mathrm{Zn}$ & $\mathrm{Pb}$ & $\mathrm{Cd}$ & $\mathrm{Cr}$ & As \\
\hline $\mathrm{Cu}$ & 1.00 & & & & & \\
\hline $\mathrm{Zn}$ & -0.14 & 1.00 & & & & \\
\hline $\mathrm{Pb}$ & -0.15 & 0.21 & 1.00 & & & \\
\hline $\mathrm{Cd}$ & $0.83^{* *}$ & -0.15 & -0.06 & 1.00 & & \\
\hline $\mathrm{Cr}$ & 0.21 & -0.03 & $0.42^{*}$ & $0.59^{* *}$ & 1.00 & \\
\hline As & $0.91^{* *}$ & -0.39 & -0.31 & $0.89^{* *}$ & 0.24 & 1.00 \\
\hline \multicolumn{7}{|c|}{ Rotated loading matrix } \\
\hline & \multicolumn{2}{|c|}{1} & 2 & 1 & \multicolumn{2}{|c|}{2} \\
\hline $\mathrm{Cu}$ & \multicolumn{2}{|c|}{0.91} & -0.06 & 3.03 & \multicolumn{2}{|r|}{50.51} \\
\hline $\mathrm{Zn}$ & \multicolumn{2}{|c|}{-0.34} & 0.39 & 1.54 & \multicolumn{2}{|r|}{25.66} \\
\hline $\mathrm{Pb}$ & \multicolumn{2}{|c|}{-0.19} & 0.86 & & & \\
\hline $\mathrm{Cd}$ & \multicolumn{2}{|c|}{0.96} & 0.20 & & & \\
\hline $\mathrm{Cr}$ & \multicolumn{2}{|c|}{0.45} & 0.76 & & & \\
\hline As & \multicolumn{2}{|c|}{0.97} & -0.20 & & & \\
\hline
\end{tabular}

Significant values $(p<0.05)$ are marked with a asterisk $\left(^{*}\right)$; Significant values $(p<0.01)$ are marked with double asterisks $\left.{ }^{* *}\right)$

directly adjacent to high population density towns. Due to the lack of drainage facilities, pollutants (including heavy metals) from carwashing bays, piers and industrial parks often wash down the river bank and were transported into the river during rainfall.

Heavy metal pollution assessment : The calculated $I_{\text {geo }}$ values in the mainstream Le'An River are illustrated in Fig. 5. The $I_{\text {geo }}$ values of heavy metals showed similarities with their concentrations. The $I_{\text {geo }}$ values for all elements in the BA were negative and were grouped in class 0 . The $I_{\text {geo }}$ values for UA fell into classes 4, 5 and 6, indicating that these areas experienced high to very high pollution. $\mathrm{S} 6$ had maximum $\mathrm{I}_{\text {gee }}$ values for $\mathrm{Cu}, \mathrm{Cd}$ and As, which fell into classes 5-6. Based on the $\mathrm{I}_{\text {geo }}$ evaluation criterion, the sediments at all sites in UA and MA were considered to be highly polluted. The degree of heavy metal pollution in the surface sediments were in the following order: $\mathrm{Cd}>\mathrm{Cu}>\mathrm{Pb}>\mathrm{Zn}$ $>$ As $>$ Cr. Following the method of Tomlinson et al. (1980), the PLI values for each site, zone and for the entire Le'An River were calculated. The $\mathrm{PLI}_{\text {zone }}$ value of BA was 0.77 , which implies that these areas were unpolluted. Not accounting for S5, the UA showed the highest $\mathrm{PLI}$ zone value, followed by $\mathrm{MA}$ and $\mathrm{DA}$. Although there are discrepancies in the PLI values for the BA, MA and DA, all the sampling sites in these areas fall into the class III type, indicating very high levels of contamination. Consequently, sampling sites S6, S17 and S9 had three highest PLI values of $30.84,26.31$ and 24.39 , respectively.

The calculated RSP values based on the ratios of secondary phase and primary phase method are presented in Fig. 6, in which sub Fig. A shows $\mathrm{Cu}, \mathrm{Zn}$ and $\mathrm{Cd}$ with higher RSP values and Fig. B shows $\mathrm{Pb}, \mathrm{Cr}$ and $\mathrm{As}$ with slightly lower RSP values. The RSP values for all the measured trace elements in the 
BA fell in Grade 1 with negative values, indicating that these areas are unpolluted. This result is consistent with the previous conclusion. However, the RSP values for the other sites greatly exceeded the values needed for Grade 4, thus reflecting a high level of pollution. The degree of pollution generally increased in the following order : DA $<M A<U A$. In particular, high-pollution areas were concentrated from S6 to S12. The RSP values in these areas were greater than 20 and several locations showed values as high as 50 , which are much higher than the severely polluted evaluation standard. After S13, heavy metal pollution decreased rapidly and was stabilized.

Chernoff faces are a useful tool for scientific and information visualization (Chernoff, 1972). Chernoff faces can represent K-dimensional multivariate data with facial features, such as length of a nose or curve of a smile. In the present study, seven variables were selected to represent six heavy metals and $P L I$ values. The nose length, smile curve, width of the mouth, eye width, eyebrow angle, brow width and face shape were used to reflect seven variables. Among these, changes in the nose length, eye width and brow width are sensitive and are used to represent the heavily polluted $\mathrm{Cu}, \mathrm{Cd}$ and $\mathrm{As}$. After conversion of the original data using the formula, the final Chernoff faces for 22 sampling sites are shown in Fig. 7. The last face was drawn using the global-scale geochemical background values as a standard chromatogram (Hamon et al., 2004). The degree of pollution can be seen directly from the changes in the features of different face parts (Fig. 7). S1 to S5 can be grouped into the same cluster with the geochemical background value face (BK) based on facial features, indicating that no obvious pollution has occurred in these areas. This also shows that the BA can be used as a background reference area for the Le'An River basin. Compared to the BK features, longer noses, wider eyes and brows were seen from S6 to S20. The longest nose and eyebrow and the widest eye were all drawn on the $\$ 6$ face, indicating maximum $\mathrm{Cu}, \mathrm{Cd}$ and $\mathrm{As}$ values. The longest smile curve and mouth appear on S9 and S17 faces, respectively. S21 and S22 had wider mouth curves compared to the standard features. In general, the features of seven variables from S6-S22 changed to different degrees. To create a Chernoff face for the present study, the assignment of variables and perception of facial characteristics were made deliberately. Thus, these sensitive features were useful for visualizing changes in a measurement compared with that of BK.

The present study demonstrates that the Le'An River is experiencing severe heavy metal pollution largely from anthropogenic sources. Mining activities and various manufacturing enterprises contribute most of the contaminants. Different assessment methods and standards reveal higher toxicity of the surface sediments in these areas, mainly due to a higher percentage of secondary phases or bioavailability ratio of pollutants. Chernoff faces were used as a useful tool for visualization of pollutants data.

\section{Acknowledgments}

This study was supported by National Natural Science Foundation of China (51469017; 51579127; 51769015), Jiangxi
Provincial Technology Department (20171ACB21050), Jiangxi Provincial Education Department (GJJ161094), Open Foundation of JiangXi Engineering Research Center of Water Engineering Safety and Resources Efficient Utilization (OF201608) and the Fundamental Research Funds for the Central Universities (No. 2017B20514).

\section{References}

Bryan, G.W. and W.J. Langston: Bioavailability, accumulation and effects of heavy metals in sediments with special reference to United Kingdom estuaries: Areview. Environ. Pollut., 76, 89 (1992).

Chabukdhara, M. and A.K. Nema: Assessment of heavy metal contamination in Hindon River sediments : A chemometric and geochemical approach. Chemosphere, 87, 945-953 (2012).

Chen, H., R. Chen, Y. Teng and J. Wu : Contamination characteristics, ecological risk and source identification of trace metals in sediments of the Le'An River (China). Ecotox. Environ. Safe., 125, 85-92 (2016).

Chen, J. and F. Wang: Chemical composition of river particulates in eastern China. GeoJournal, 40, 31-37 (1996).

Chernoff, $\mathrm{H}$.: The use of faces to represent points in K-dimensional space graphically. J. Am. Stat. Assoc., 68, 361-368 (1972).

Dou, Y., J. Li, J. Zhao, B. Hu and S. Yang: Distribution, enrichment and source of heavy metals in surface sediments of the eastern Beibu Bay, South China Sea. Mar. Pollut. Bull., 67, 137 (2013).

Hamon, R.E., M.J. Mclaughlin, R.J. Gilkes, A.W. Rate, B. Zarcinas and A. Robertson: Geochemical indices allow estimation of heavy metal background concentrations in soils. Global Biogeochem. Cy., 18, 1-6 (2004).

Hasayen, K., B. Al-Osaimi, A. Aljohany and H. Al-Jawdah: Spatial distribution of heavy metals in water, soil and anurans' livers from Al-Hayr area - Riyadh, Saudi Arabia. J. Environ. Biol., 38, 231-236 (2017).

Hilson, G. and B. Murck: Sustainable development in the mining industry: Clarifying the corporate perspective. Resour. Policy, 26, 227-238 (2000).

Idris, A.M., T.O. Said, A.A. Omran and K.F. Fawy: Combining multivariate analysis and human risk indices for assessing heavy metal contents in muscle tissues of commercially fish from Southern Red Sea, Saudi Arabia. Environ. Sci. Pollut. R., 22, 17012-17021 (2015).

Jalali, M. and N. Hemati: Chemical fractionation of seven heavy metals ( $\mathrm{Cd}, \mathrm{Cu}, \mathrm{Fe}, \mathrm{Mn}, \mathrm{Ni}, \mathrm{Pb}$ and $\mathrm{Zn}$ ) in selected paddy soils of Iran. Paddy Water Environ., 11, 299-309 (2013).

Ji, C.K., Z.D. Nejad and M.C. Jung: Arsenic and heavy metals in paddy soil and polished rice contaminated by mining activities in Korea. Catena, 148, 92-100 (2017).

Ji, Y., J. Zhang, X. Huang, C. Bai and X. Chen: Investigation and assessment of heavy metals in surface sediments of Ganjiang River, China. J. Environ. Biol., 35, 1173-1179 (2014).

Ji, Y., J. Zhang, R. Li, B. Pan, L. Zhang and X. Chen: Distribution and partitioning of heavy metals in sediments of the Xinjiang River in Poyang Lake Region, China. Environ. Prog. Sustain., 34, 713-723 (2015).

Ji, Y., J. Zhang, B. Pan and X. Chen: Heavy-metal distribution and risk assessment in surface sediments from Xinjiang River in Poyang Lake Region, China. Int. J. Earth Sci. Eng., 7, 583-594 (2014).

Mehr, M.R., B. Keshavarzi, F. Moore, R. Sharifi, A. Lahijanzadeh and M. Kermani : Distribution, source identification and health risk assessment of soil heavy metals in urban areas of Isfahan Province, Iran. J. Afr. Earth Sci., 132, 16-26 (2017)

Mohammad Ali, B.N., C.Y. Lin, F. Cleophas, M.H. Abdullah and B. Musta: 
Assessment of heavy metals contamination in Mamut river sediments using sediment quality guidelines and geochemical indices. Environ. Monit. Assess., 187, 4190 (2015).

Muller, G.: Index of geoaccumulation in sediments of the Rhine River. Geo Journal, 2, 108-118(1969).

Samanta, S., K. Mitra, K. Chandra, K. Saha, S. Bandopadhyay and A. Ghosh: Heavy metals in water of the rivers Hooghly and Haldi at Haldia and their impact on fish. J. Environ. Biol., 26, 517 (2005).

Sheoran, A.S. and V. Sheoran: Heavy metal removal mechanism of acid mine drainage in wetlands: A critical review. Miner. Eng.,19, 105116 (2006).

Soto-Jiménez, M.F. and A.R. Flegal: Metal-contaminated indoor and outdoor housedust from a neighborhood smelter area in Torreón, Mexico. Procedia Environ. Sci., 4, 134-137 (2011).

Tomlinson, D.L., J.G. Wilson, C.R. Harris and D.W. Jeffrey: Problems in assessment of heavy metals in estuaries and the formation of pollution index. Helgoland Mar. Res., 33, 566-575 (1980).

Wen, L.F., Y. Wen, W.W. Zhi, G.S. Chang and C. Zhong: Pollution of heavy metals in the Pearl River Estuary and its assessment of potential ecological risk. Mar. Environ. Sci., 21, 34-38 (2002).

Yu, Y., H. Wang, Q. Li, B. Wang, Z. Yan and A. Ding: Exposure risk of rural residents to copper in the Le'An River Basin, Jiangxi Province, China. Sci. Total Environ., 548, 402-407 (2016).

Zahra, A., M.Z. Hashmi, R.N. Malik and Z. Ahmed: Enrichment and geoaccumulation of heavy metals and risk assessment of sediments of the Kurang Nallah-Feeding tributary of the Rawal Lake Reservoir, Pakistan. Sci. Total Environ., 470, 925-933 (2014).

Zhang, W., H. Feng, J. Chang, J. Qu, H. Xie and L. Yu: Heavy metal contamination in surface sediments of Yangtze River intertidal zone : An assessment from different indexes. Environ. Pollut., 157, 1533-43 (2009).

Zhu, L., J. Liu, S. Xu and Z. Xie: Deposition behavior, risk assessment and source identification of heavy metals in reservoir sediments of Northeast China. Ecotox. Environ. Safe., 142, 454-463 (2017).

Zimmerman, A.J. and D.C. Weindorf: Heavy metal and trace metal analysis in soil by sequential extraction : A review of procedures. Int. J.Anal. Chem., 2010, 387803 (2010). 